Supporting Information

\title{
Origin of transcrystallinity and nucleation kinetics in polybutene-1/fiber
}

\section{composites}

Wei Wang, Bao Wang, Agnieszka Tercjak, Alejandro J. Müller, Zhe Ma, Dario Cavallo,

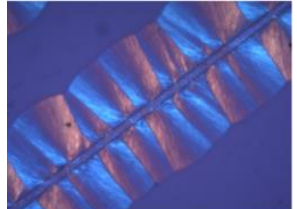

$110^{\circ} \mathrm{C}$

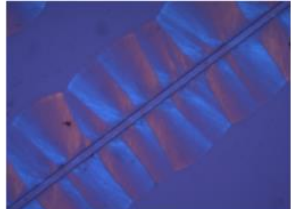

$116.5^{\circ} \mathrm{C}$

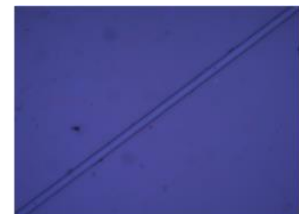

$119.3^{\circ} \mathrm{C}$

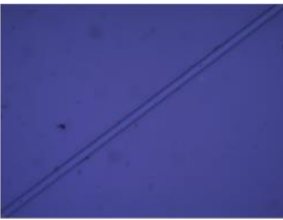

$120.8^{\circ} \mathrm{C}$

Figure S1. Polarized optical micrographs acquired during heating for PB-1 crystals formed on the surface of PP fiber at $91{ }^{\circ} \mathrm{C}$.
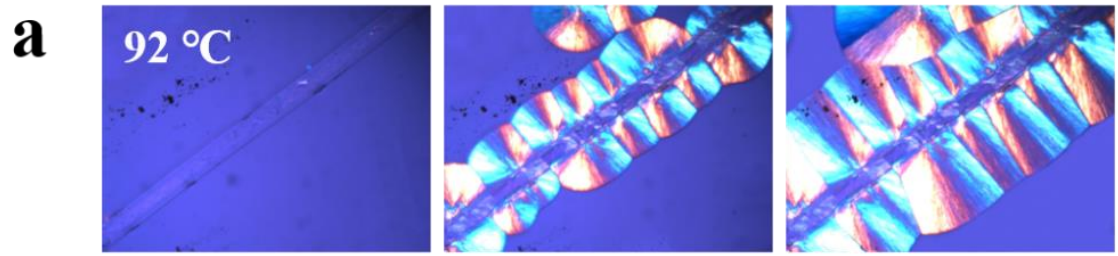

b
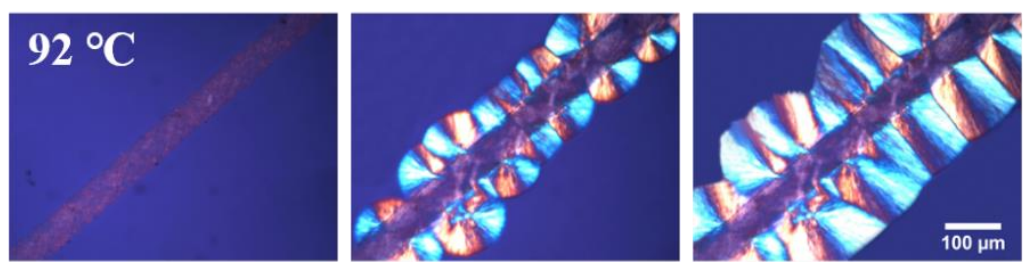

$\boldsymbol{O} S$

$90 s$

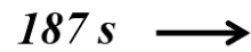

Figure S2. Polarized optical micrographs of PB-1 form II crystallized on the surface of (a) PLLA and (b) SC fibers during isothermal crystallization at $92{ }^{\circ} \mathrm{C}$. 
a

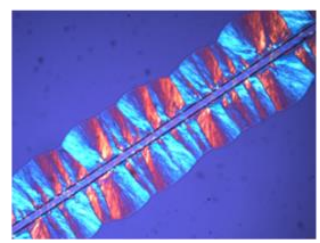

$92{ }^{\circ} \mathrm{C}$

b

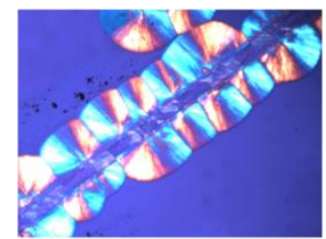

$92{ }^{\circ} \mathrm{C}$

C

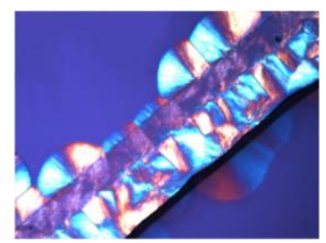

$92^{\circ} \mathrm{C}$

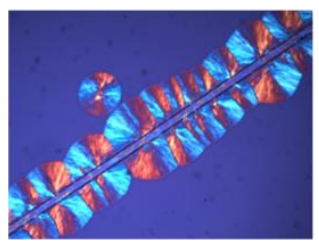

$93^{\circ} \mathrm{C}$

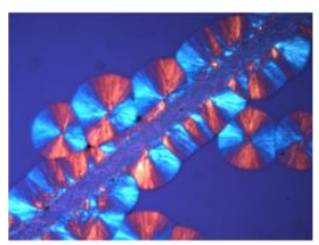

$93{ }^{\circ} \mathrm{C}$

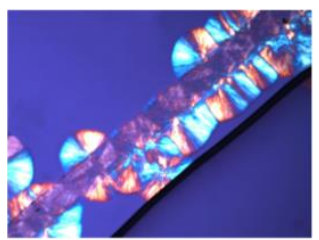

$93^{\circ} \mathrm{C}$

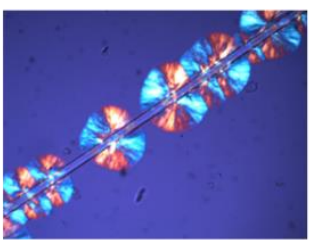

$94{ }^{\circ} \mathrm{C}$

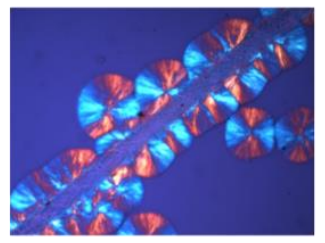

$94{ }^{\circ} \mathrm{C}$

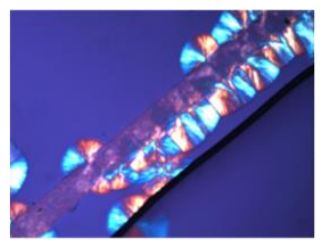

$94{ }^{\circ} \mathrm{C}$

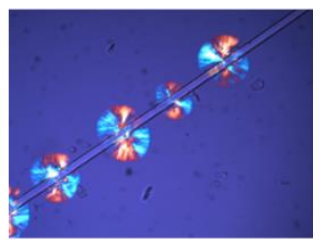

$95^{\circ} \mathrm{C}$

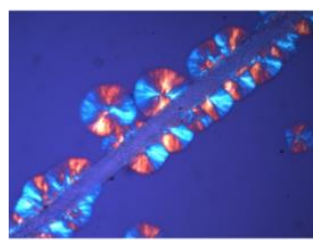

$95^{\circ} \mathrm{C}$

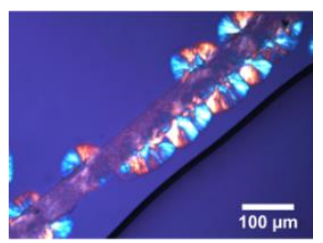

$95{ }^{\circ} \mathrm{C}$

Figure S3. Morphological changes of PB-1 matrix crystallized on the surface of (a) PP, (b) PLLA and (c) SC fibers for $90 \mathrm{~s}$ at selected $T_{c}$ values.

$\mathbf{a}$

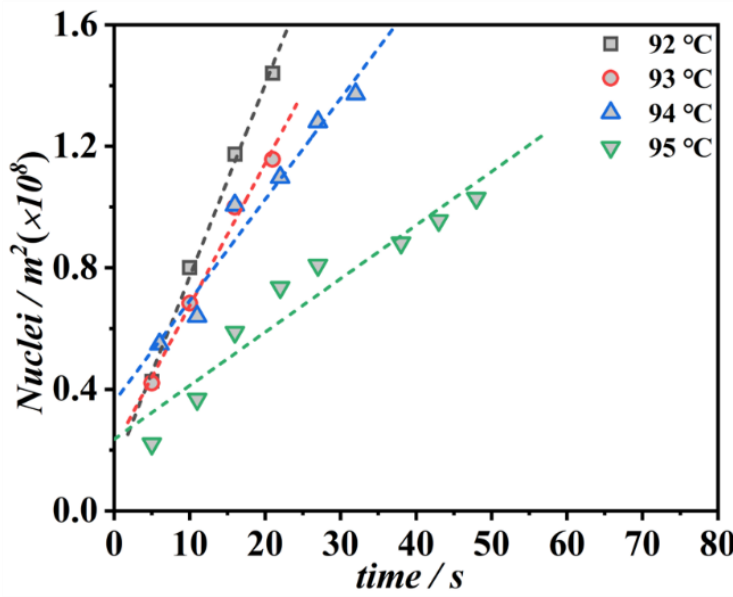

b

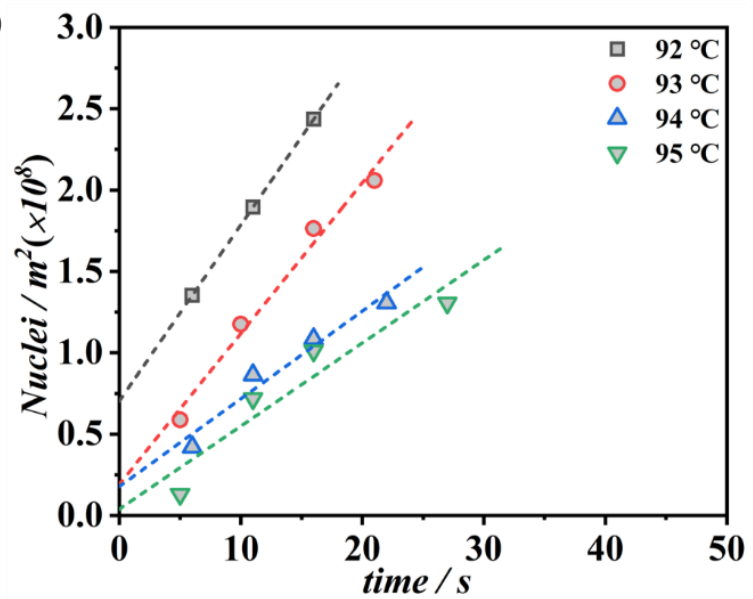




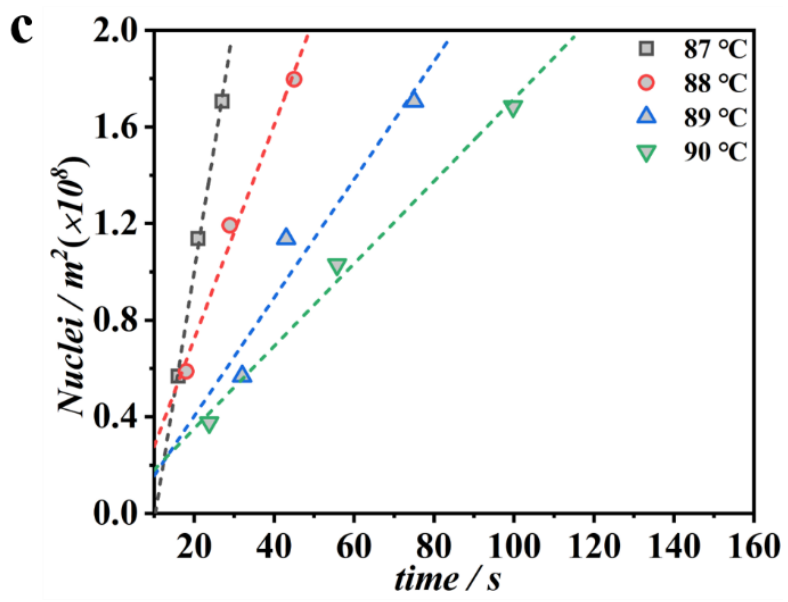

Figure S4. Nucleation density of PB-1 Form II on the surface of (a) SC, (b) glass and (c) carbon fibers as a function of time for specimens crystallized at selected $T_{c}$ values.

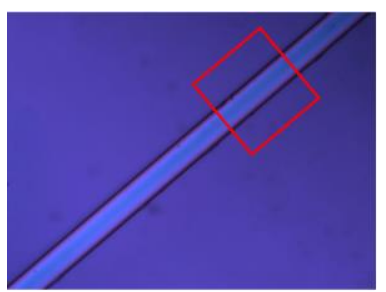

$\boldsymbol{O} \mathrm{s}$

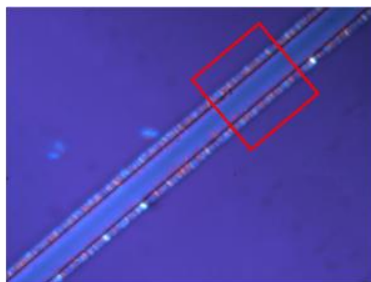

$90 s$

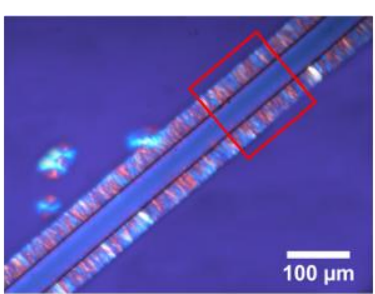

$187 \mathrm{~s}$

Figure S5. Polarized optical micrographs of PB-1 nucleated on the surface of the Form I fiber at different times during crystallization at $101{ }^{\circ} \mathrm{C}$. The red rectangular region is the selected area for light intensity calculation.
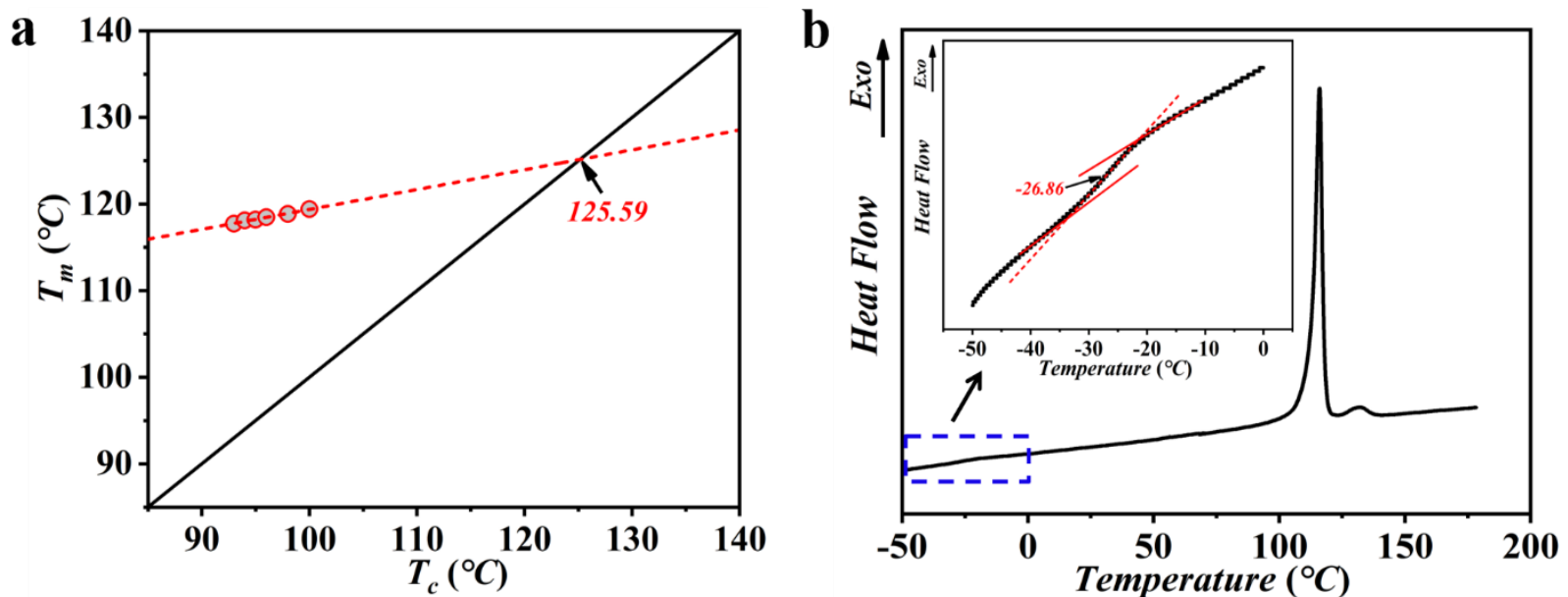

Figure S6. (a) Equilibrium melting point derived from the Hoffman-Weeks methods and (b) glass transition temperature of PB-1. 

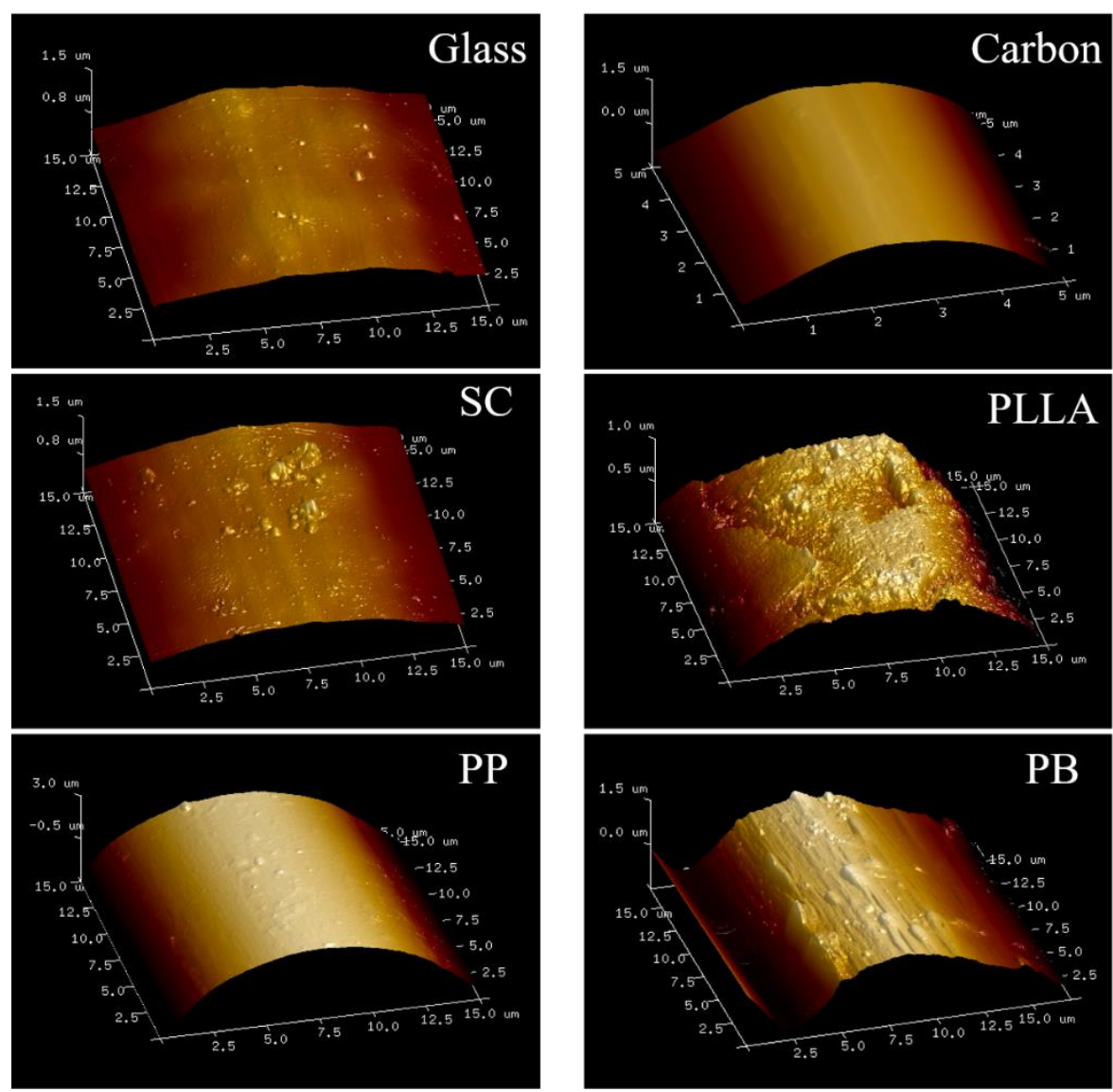

Figure S7. AFM height images of different fiber surfaces.

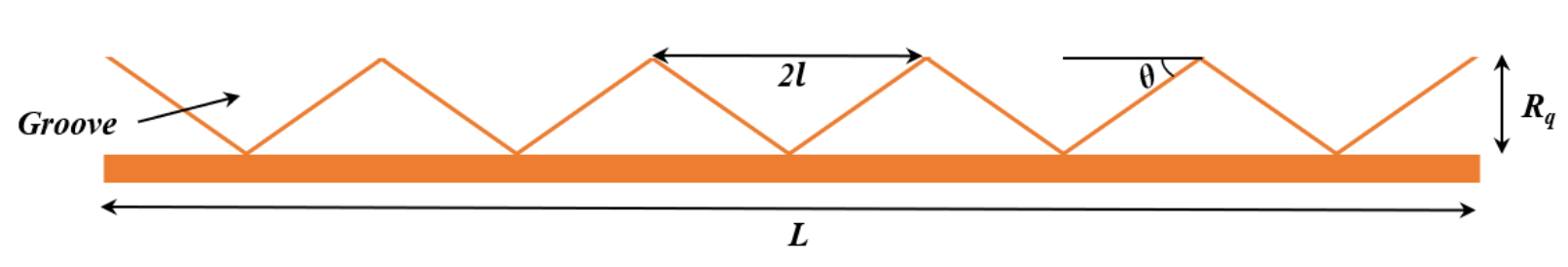

Figure S8. Schematic of parameters used for calculation of the number of the potential nucleation sites of fiber. 


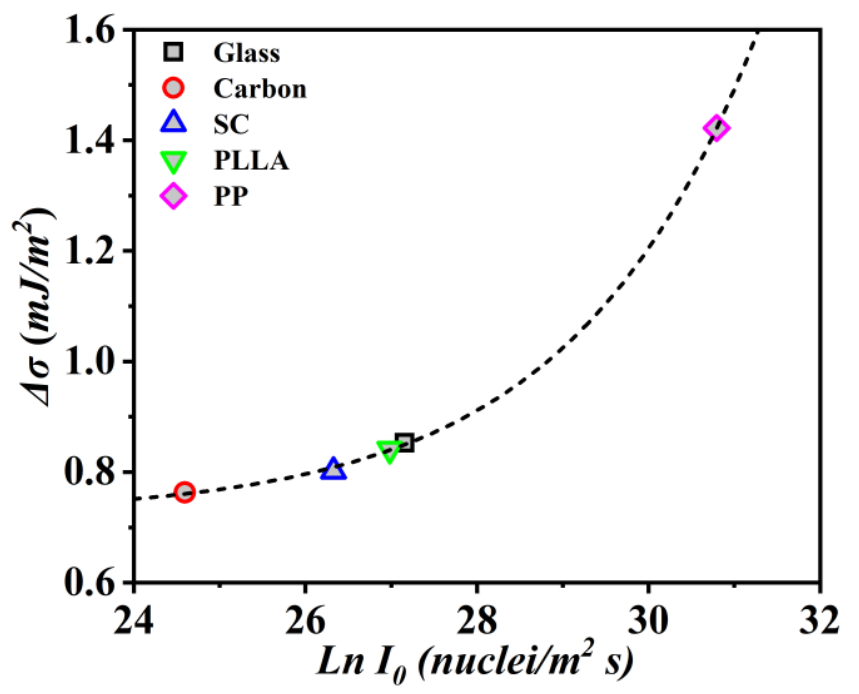

Figure S9. Plot of interfacial free energy difference $(\Delta \sigma)$ as a function of the logarithm of potential nucleation sites $\left(\operatorname{Ln}\left(I_{0}\right)\right)$ for most fibers. 